\title{
Performance and Preparation of the Electroless Ni Wood-Based Composites
}

\author{
Yanfei Pan, ${ }^{\mathrm{a}, \mathrm{b}, 1}$ Dingwen Yin, ${ }^{\mathrm{a}, \mathrm{b}, 1}$ Surigala, ${ }^{\mathrm{a}, \mathrm{b}}$ Yinan Hao, ${ }^{\mathrm{a}, \mathrm{b}}$ Dong Xing, ${ }^{\mathrm{b}}$ Sufen Hao, ${ }^{\mathrm{a}, \mathrm{b}}$ \\ Xiaofang Yu, a,b Haibiao Yu, a,b and Jintian Huang a,b,
}

\begin{abstract}
A wood-based composite exhibiting excellent electromagnetic shielding performance was prepared by electroless Ni plating. The properties of the material were characterized by a series of tests. The results showed that the growth route of Ni particles was first arranged along the inherent grain of the wood to form a banded metal layer. With extension of the duration of electroless plating, the growth of Ni particles gradually extended around and filled the pores between wood fibers, and finally formed flake-shape structure. The metal coatings formed a strip along the inherent grain of the wood surface and then changed into a sheet until it covered the entire wood surface. The coatings resistance was from $12 \Omega$ to $0.5 \Omega$ with the increase in duration of electroless plating. When the duration was $20 \mathrm{~min}$, the composite coating resistance was $0.5 \Omega$. Here, the contact angle of composite coatings was $98.3^{\circ}$ when the plating time was 15 min. When the wood surface was modified via two depositions of $\mathrm{Ni}$, the average electromagnetic shielding value of the composites was over $80 \mathrm{~dB}$ in the frequency ranging from $0.3 \mathrm{kHz}$ to $3.0 \mathrm{GHz}$.
\end{abstract}

Keywords: Electroless Ni; Wood; Resistance gradient; Electromagnetic shielding

Contact information: a: College of Material Science and Art Design, Inner Mongolia Agricultural University, Hohhot, 010018, China; b: Inner Mongolia Key Laboratory for Sand Shrubs Fibrosis and Energy Development and Utilization, Hohhot, 010018, China; 1: These authors contributed equally to this work; *Corresponding author: jintian_h@163.com

\section{INTRODUCTION}

As a material with light weight, easy preparation, and excellent shielding efficiency, wood-metal composite materials have developed rapidly in preparation technology. Covering a layer of metal on the wood surface can improve the electromagnetic shielding effectiveness, temperature resistance, wear-resistance, and strength of wood (Zhou 2011). In general, there are many methods for surface metallization of non-metallic materials, mainly vacuum thermal evaporation deposition, vacuum evaporation, sputtering, chemical vapor deposition, physical vapor deposition, electrophoresis, electroplating, chemical plating, and replacement plating. Electroless plating is widely used due to its simple operation and low cost (Zhou 2011).

In the 1980s, Japanese scholars carried out research on the chemical plating of wood. The research demonstrated the relationship between the volume resistivity of the particle board and the electromagnetic shielding effect. With a decreased volume resistivity of the particle board, the electromagnetic shielding becomes better. Li (2019) prepared a $\mathrm{Cu}$ film and a $\mathrm{ZnO}$ film on the surface of the wood veneer by magnetron sputtering on Pinus sylvestris. Shi (2016) added nanoparticles $\mathrm{Al}_{2} \mathrm{O}_{3}, \mathrm{SiO}_{2}$, and $\mathrm{SiC}$ to the plating solution to prepare an excellent Ni-P-nanoparticle composite coatings, using birch as the 
plating substrate. A wood-copper electromagnetic shielding material was developed with SE up to $60 \mathrm{~dB}$ (Wang et al. 2010). Qin (2015) chemically plated the wood of an artificial forest, which provided wood decoration, electric heat conduction, and electromagnetic shielding. He (2018) prepared wood/polyaniline electromagnetic shielding composite materials via in-situ polymerization. Chen (2016) used magnetic expanded graphite and wood fiber to prepare an electromagnetic shielding composite board. Zhu (2016) used waste wood chips to reprocess and use it to explore the work of replacing metal materials in certain corrosive environments, which has the effect of electrical conductivity and electromagnetic shield. Chen et al. (2019) used wood as a substrate to prepare wood-based composites with excellent elasticity and electrical conductivity by using delignification and electroless Ni plating. Wood chemical plating has been used to prepare electromagnetic shielding particle board (Wang 2017), wear-resistant materials (Pan et al. 2016), and synthetic wood reflection absorption integrated electromagnetic shielding materials (Guo 2017) by chemically plating wood with $\mathrm{Cu}$ and $\mathrm{Ni}$.

During the period of application, the surface of the wood has been chemically plated with $\mathrm{Cu}$ for several times (Guo et al. 2017; Wang et al. 2010). The electromagnetic shielding effectiveness of the composite material in the frequency range of $300 \mathrm{kHz}$ to 1.5 $\mathrm{GHz}$ can reach up to $60 \mathrm{~dB}$ (Guo 2017), which confirmed that the wood-based conductivity gradient structure could improve the absorption efficiency of electromagnetic waves. Therefore, if a controllable electromagnetic gradient multilayer structure can be developed, it is expected to break through the limitation of high absorption of electromagnetic waves by wood-based metal composite materials. However, due to the anisotropy of the anatomical structure of wood, its electrical properties are closely related to the texture (Liu and Zhao 2012). The resistivity of wood in the grain direction is greater than that in the grain direction. After electroless treatment on the wood surface, the growth rate of the surface coating in the transverse direction is faster than that in the direction following the texture (Pan et al. 2016, 2017). According to skin depth theory, the intensity of electromagnetic waves attenuates according to an exponential relationship with the increase of the incident depth of electromagnetic waves (Liang et al. 2017). The magnitude of material resistance and electrical conductivity directly affects the electromagnetic shielding effectiveness of materials (Wang et al. 2009; Liu et al. 2014; Lee et al. 2016; Sudesh et al. 2017; He et al. 2018; Li et al. 2018; Poothanari et al. 2018). Dense, continuous metal plating is very important for the preparation of high-efficiency chemically plated wooden shielding materials. Therefore, a profound understanding of the resistance gradient structure of chemical plating on the surface of the wood is the key to the preparation of efficient electromagnetic shielding materials that need to operate in a wide frequency range. At present, the electromagnetic shielding effectiveness to prepare light electromagnetic shielding materials based on wood is between 30 and $60 \mathrm{~dB}$. It is convenient and controllable to self-assemble to build a light and controllable conductivity gradient multilayer structure. The relationship between the resistance gradient of the coating and the duration of electroless plating has received insufficient research attention.

In this study, the time duration of electroless deposition of $\mathrm{Ni}$ plating was considered as an independent variable. The change rule and optimal of the resistance gradient in the process of electroless plating of $\mathrm{Ni}$ on the wood surface were analyzed relative to the performance according to the changes in the wood surface and internal micro-morphology of each time period. In addition, scanning electron micrographs were obtained as a function of deposition time, making it possible to track the progress of 
development of electrically conductive material.

\section{EXPERIMENTAL}

\section{Preparation of Specimens \\ Materials}

The fast-growing poplar wood (hardwood) was procured from Saihan district, Hohhot, China. It was later cut into $11 \mathrm{~cm}$ (diameter) $\times 0.34 \mathrm{~mm}$ (thickness) circular pieces after the wood had been soaked in water for $30 \mathrm{~min}$. Then, the wood was treated with \#600 sandpaper.

\section{Substrate pretreatment}

The circular pieces treated with \#200 sand paper were placed in a beaker containing distilled water at $100{ }^{\circ} \mathrm{C}$ for $120 \mathrm{~min}$. Then they were taken out and placed in a beaker containing distilled water $(900 \mathrm{~mL})$.

\section{Electroless Ni on wood surface}

Wood was activated with activation solution A (15 g/L nickel sulfate hexahydrate, $12 \mathrm{~mL} / \mathrm{L}$ hydrochloric acid) for $15 \mathrm{~min}$. Next, the wood was activated in solution B (15 g/L sodium borohydride, $15 \mathrm{~g} / \mathrm{L}$ sodium hydroxide) for $90 \mathrm{~s}$ and removed when no liquid was dripping. The electroless Ni was conducted. Electroless Ni solution included $33 \mathrm{~g} / \mathrm{L}$ nickel sulfate hexahydrate, $28 \mathrm{~g} / \mathrm{L}$ sodium hypophosphite, $30 \mathrm{~g} / \mathrm{L}$ trisodium citrate dihydrate, and $10 \mathrm{mg} / \mathrm{L}$ thiourea. The process was conducted at $\mathrm{pH}=9$ (adjusted with $30 \mathrm{~mL} / \mathrm{L}$ ammonia) and $60{ }^{\circ} \mathrm{C}$. After the plating solution was reconstituted, Ni was continuously electrolessly plated under the same conditions, covered with a $0.34 \mathrm{~mm}$ thick round poplar wood board, compacted, and dried at $60{ }^{\circ} \mathrm{C}$ for $4 \mathrm{~h}$.

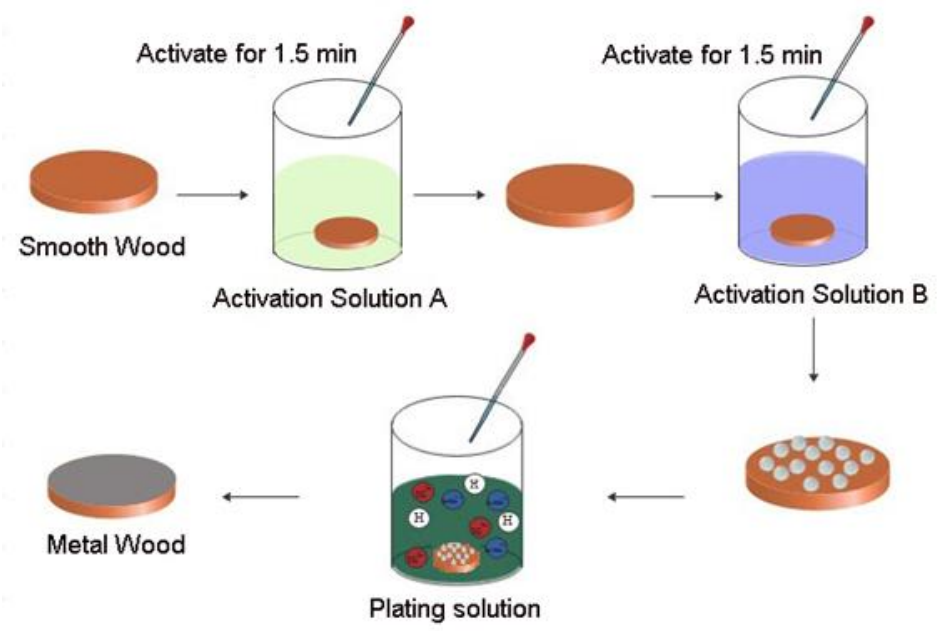

Fig. 1. Preparation of electroless Ni composite materials on wood surface

\section{Surface Characterization}

RTS-8 four-probe tester

A thin, Ni-coated wood chip was placed on the test platform of the RTS-8 fourprobe tester (Guangzhou Four Probe Technology Co. Ltd, GuangZhou, China; the probe was slowly adjusted to contact the sample. After confirming that the probe contacted the 
sample, the sheet resistance was checked in the main interface of the software to start the measurement. The wood chip sample was measured at five different positions for horizontal and straight lines, and five different points for each position. The average value for resistance was recorded.

Scanning electron microscopy (SEM)

The surface morphology of the material was characterized by scanning electron microscope (Phenom, PW-100-516, Eindhoven, Holland).

\section{Confocal microscopy}

A VK-X160 laser confocal microscope (Keyence, Osaka, Japan) was used. The samples were placed in the center of the square sample table. The settings "multiple of 20 " and "surface measurement method" were selected. The surface roughness and "3D" model were measured. These steps were repeated for five different positions for each sample. The average value was calculated.

\section{Hydrophobic test}

After dripping water on a dry sample for $30 \mathrm{~s}$, a JY-PHa contact angle measuring instrument (Chengdeyoute Testing Instrument Manufacturing Co. Ltd., Cheng De, China) was used to characterize the hydrophobic properties of the material.

\section{Electromagnetic shielding effectiveness test}

The DR-S01 shielding effectiveness test device (DR Beijing Technology Co., Ltd., Beijing, China) was used to measure the electromagnetic shielding effectiveness of the composite material at a frequency from $0.3 \times 10^{3}$ to $3.0 \times 10^{3} \mathrm{MHz}$. The thickness of the sample used for electromagnetic shielding measurement was $1.5 \mathrm{~mm}$.

\section{RESULTS AND DISCUSSION}

\section{Morphology of Electroless Ni Plating on Wood Surface}

Figure 2 shows the surface morphology of the wood surface treated with different duration of electroless plating. Figure 2a shows the pit structure of the wood. The scale of roughness of the wood was quite large, as shown in Fig. $2 b$. Figure $2 \mathrm{c}$ shows the surface morphology of electroless $\mathrm{Ni}$ on the wood surface following $1 \mathrm{~min}$ of deposition. With the extension of duration of electroless Ni plating, the white strip area on the wood surface gradually decreased, while the black strip gradually increased (Figs. 2e, 2g, 2i, and 2k). The black material was generally distributed along with the wood texture, and the morphology gradually became flat in the 3D image with the extension of duration of plating (Figs. 2d, 2f, 2h, 2j, and 2l). Previous experimental results determined that the black material is Ni particles. Ni particles grow quickly on higher wood surface and are gradually deposited in areas, which makes the wood surface smooth and flat (Pan et al. 2016). Table 1 showed that as the time of electroless $\mathrm{Ni}$ was prolonged, the surface roughness of the wood surface gradually decreased (Fig. 2), further verifying the effect of Ni content on the rate of electroless plating reaction. As the duration of electroless plating increased, $\mathrm{Ni}$ particles on the wood surface gradually increased and filled the defects of the wood, making the originally uneven wood surface smooth and flat. When the electroless plating 
time was $20 \mathrm{~min}$, the surface roughness of the metal coating on the wood surface was 8.014 $\mu \mathrm{m}$. The wood surface tended to be flat, which demonstrated that the rate of metal ion deposition on the wood surface is determined by the catalysis of the substrate and the deposition layer (Nagasawa et al. 1999). With the extension of the duration of plating, the substrate surface was gradually coated with a layer of metal $\mathrm{Ni}$. The deposited Ni particles autocatalyze $\mathrm{Ni}^{2+}$. With the extension of the duration of plating, the catalytic ability of the deposited Ni matrix was enhanced.

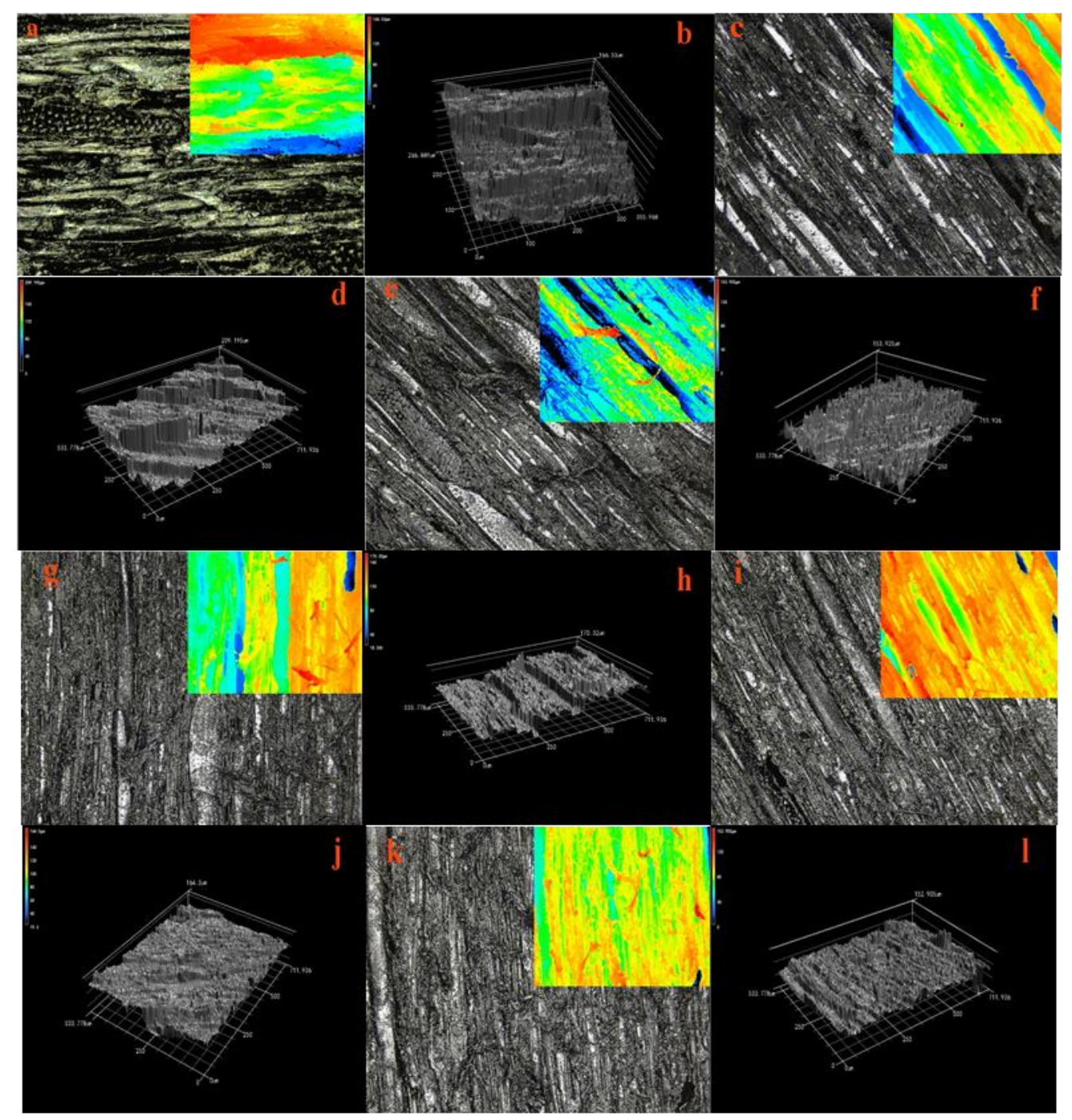

Fig. 2. The shape of the laser copolymerization microscope on the surface of the wood at different electroless plating times is $200 \times(\mathrm{a}: 0 \mathrm{~min}, \mathrm{c}: 1 \mathrm{~min}, \mathrm{e}: 5 \mathrm{~min}, \mathrm{~g}: 10 \mathrm{~min}, \mathrm{i}: 15 \mathrm{~min}, \mathrm{k}: 20 \mathrm{~min}$ inset shows a 3-D picture, a to $\mathrm{k}$ depth diagrams from different durations of electroless plating) 
Table 1. Roughness of Metal Coating on Wood Surface

\begin{tabular}{|c|c|}
\hline Electroless Ni time & Sa $(\mu \mathrm{m})$ \\
\hline 0 & 26.333 \\
\hline 1 & 21.671 \\
\hline 5 & 20.205 \\
\hline 10 & 19.543 \\
\hline 15 & 10.029 \\
\hline 20 & 8.014 \\
\hline
\end{tabular}

\section{SEM Morphology of Composite Materials with Different Electroless Ni Plating Time}

Figure 3 shows the surface morphology of the electroless Ni layer at different durations of electroless plating. It is evident that the pit structure of the wood was clearly visible when the wood was treated without electroless Ni (Fig. 3a). When the wood was treated with electroless $\mathrm{Ni}$ for $1 \mathrm{~min}$, the wood surface was uneven, and the metal layer was unevenly distributed (Fig. 3b). With the extension of the duration of plating, the surface of the wood tended to be flat, and the size of the surface particles gradually increased. The pit structure of the wood tended to be covered, and the surface brightness gradually increased. The growth route of the Ni particles was first arranged on the strip metal layer along with the inherent pit structure of the wood (Figs. $3 \mathrm{c}$ and $3 \mathrm{~d}$ ). The growth gradually extended to the surroundings, and then it filled the pores between the fibers, eventually forming a lamellar structure, and then forming a lamellar shape until covering the entire wood surface (Figs. 3e and 3f).
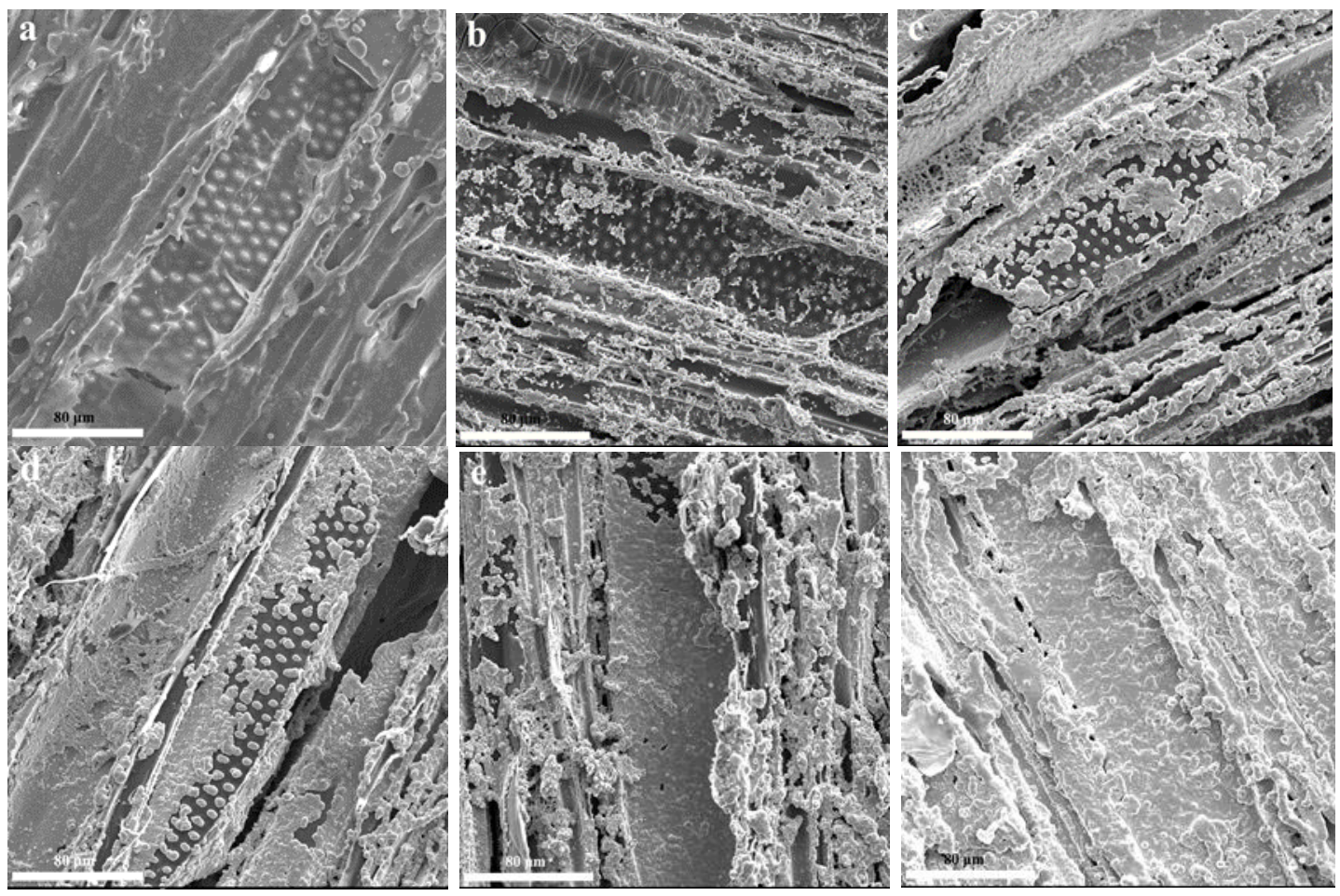

Fig. 3. Surface morphology of wood at different durations of electroless plating (a: $0 \mathrm{~min}, \mathrm{~b}: 1$ $\min , \mathrm{c}: 5 \mathrm{~min}, \mathrm{~d}: 10 \mathrm{~min}, \mathrm{e:} 15 \mathrm{~min}, \mathrm{f}: 20 \mathrm{~min}$ ) 
The wood surface was gradually covered with a layer of Ni coatings. As Ni particles can promote the autocatalytic function, the catalytic capacity of wood surface coating was gradually enhanced. With the improvement of the wood substrate autocatalytic ability, the Ni content of the wood surface also increased, and the thickness of the coating on the wood surface gradually increased.

\section{The Resistance of Composite Materials}

Figure 4 shows the relationship between the resistance of the chemical plating layer on the wood surface under different durations of electroless treatment. When the duration of plating was extended from 0 to $5 \mathrm{~min}$, the horizontal and linear resistance gradually decreased from a large resistance value of $12 \Omega$ to $1 \Omega$. With the extension of the duration, the resistance fluctuated within the range of 0.5 to $1 \Omega$. When the duration was over 10 min, the resistance change of the coating layer on the wood surface was smaller, and the horizontal surface resistance of the wood surface was greater than the resistance value. The main reason is that $\mathrm{Ni}^{2+}$ was rapidly reduced and a large amount of $\mathrm{Ni}$ quickly accumulated on the wood surface with the increase of the time of electroless $\mathrm{Ni}$ from 0 to $5 \mathrm{~min}$. The metal layer was distributed along with the wood texture, covering the entire wood surface. Comparing the resistance between horizontal grains and along grains, the resistance value of horizontal grains was generally larger than that of along grains because $\mathrm{Ni}^{2+}$ will deposit along the grain of the wood and gradually extended laterally along the grain to the entire wood surface. Therefore, the resistance along the grain of the chemical plating layer on the wood surface was smaller than the horizontal grain (Liu and Zhao 2012).

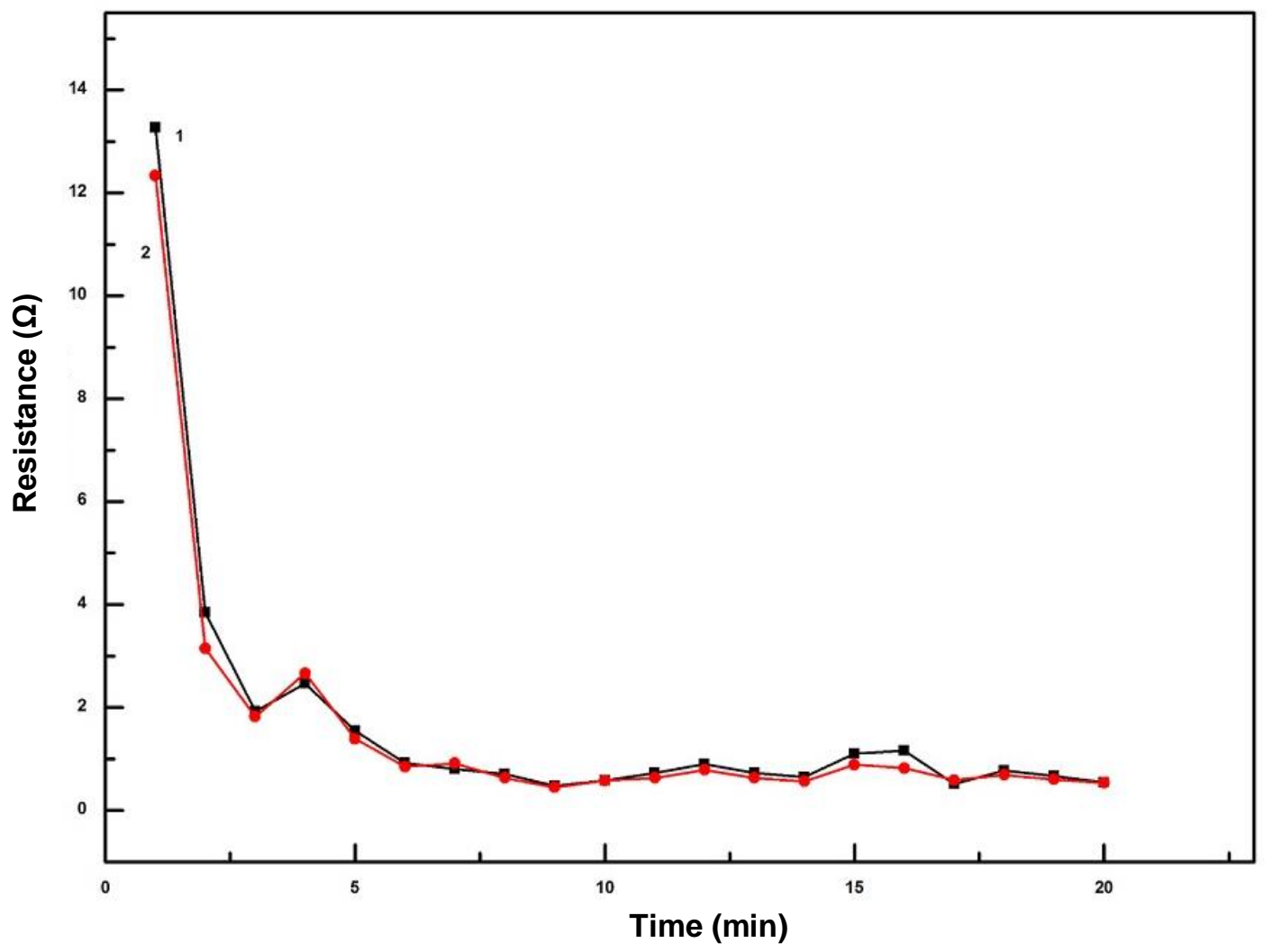

Fig. 4. The relationship between different durations of electroless Ni plating and the resistance of the composite material ( 1 the transverse grain resistance, 2 the longitudinal grain resistance) 


\section{XRD}

Figure 5 shows the XRD spectra of the surface coating at different durations of electroless plating. The duration was set to $0.5 \mathrm{~min}, 1 \mathrm{~min}, 2 \mathrm{~min}$, and $3 \mathrm{~min}$. There was a strong diffraction peak at $2 \theta=23^{\circ}$, the characteristic peak of wood (Cherian et al. 2010). With the extension of the duration of plating, a strong diffraction peak at $2 \theta=23^{\circ}$ gradually weakened, and the spectrum had a significant change at $2 \theta=45,53$, and $78^{\circ}$. The intensity of the diffraction peak at this place was enhanced. When the crystalline structure of the composite coating on the wood surface changed, the crystal structure of the composite coating became stronger (Amer 2014; Pan et al. 2016). The diffraction intensity of the crystallization peak was wide and sharp when the duration of electroless plating exceeded 8 min, which further verified that the metal deposited on the wood surface gradually increased as the duration of plating increased. The surface of the coating layer tended to be flat. Therefore, when the duration of plating was $20 \mathrm{~min}$, the wood surface was gradually covered with a metal layer and the surface crystal structure was good, indicating that the wood surface coating gradually changed from amorphous to crystalline.

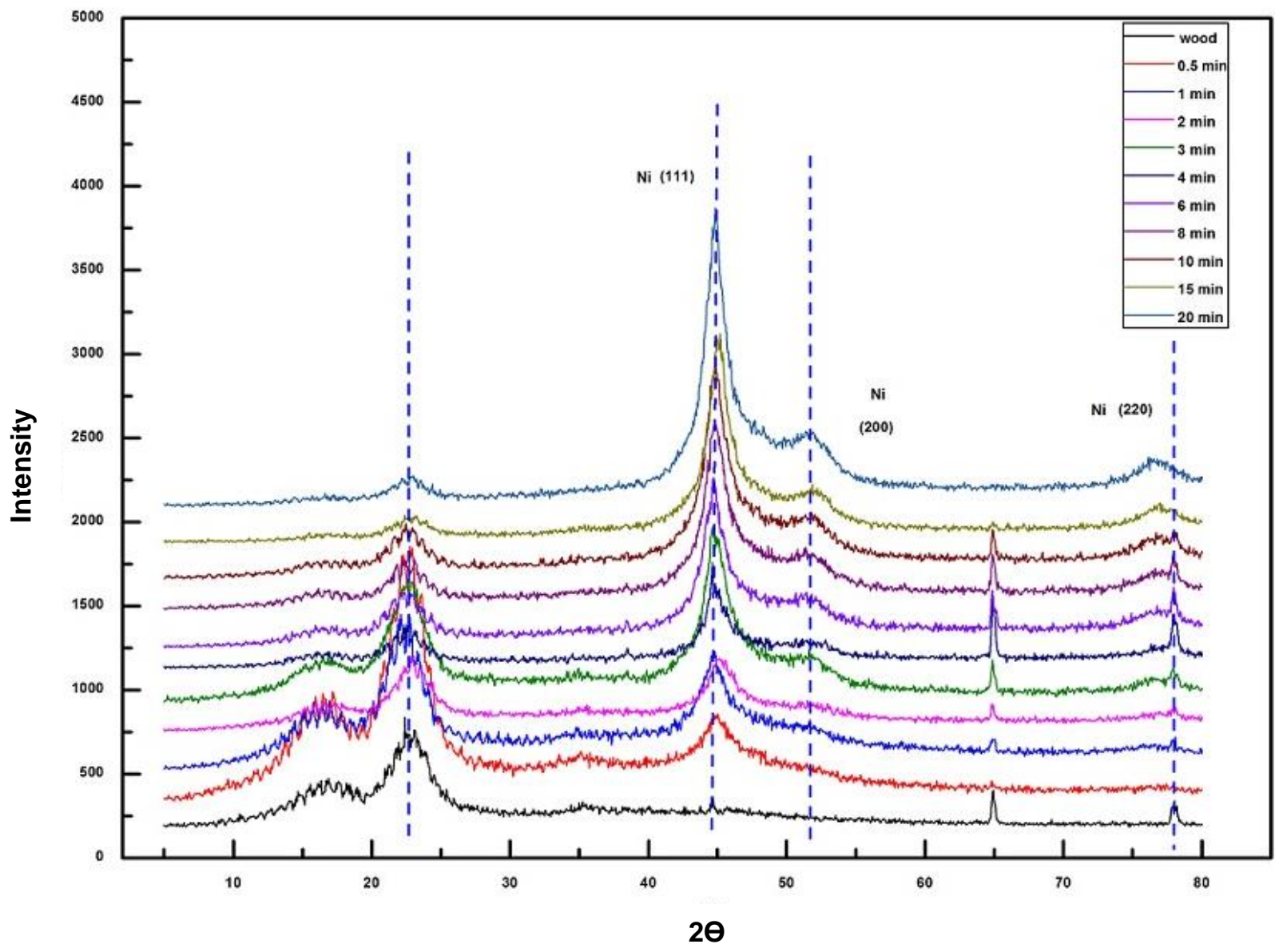

Fig. 5. Relationship between duration of electroless plating and crystal structure

\section{Hydrophobic Performance}

Figure 6 shows the surface hydrophobic properties of wood-based metal composites treated with different durations of electroless Ni plating. When the processing time was $0 \mathrm{~min}, 1 \mathrm{~min}, 5 \mathrm{~min}, 10 \mathrm{~min}, 15 \mathrm{~min}$, and $20 \mathrm{~min}$, the contact angles of wood- 
based metal composites were 67.4, 69, 96.7, 93.7, 98.3, and 96.2 (Table 2), respectively. When the duration of plating was $15 \mathrm{~min}$, the hydrophobic properties of wood-based metal composites were the highest. Here, the contact angle was up to $98.3^{\circ}$.

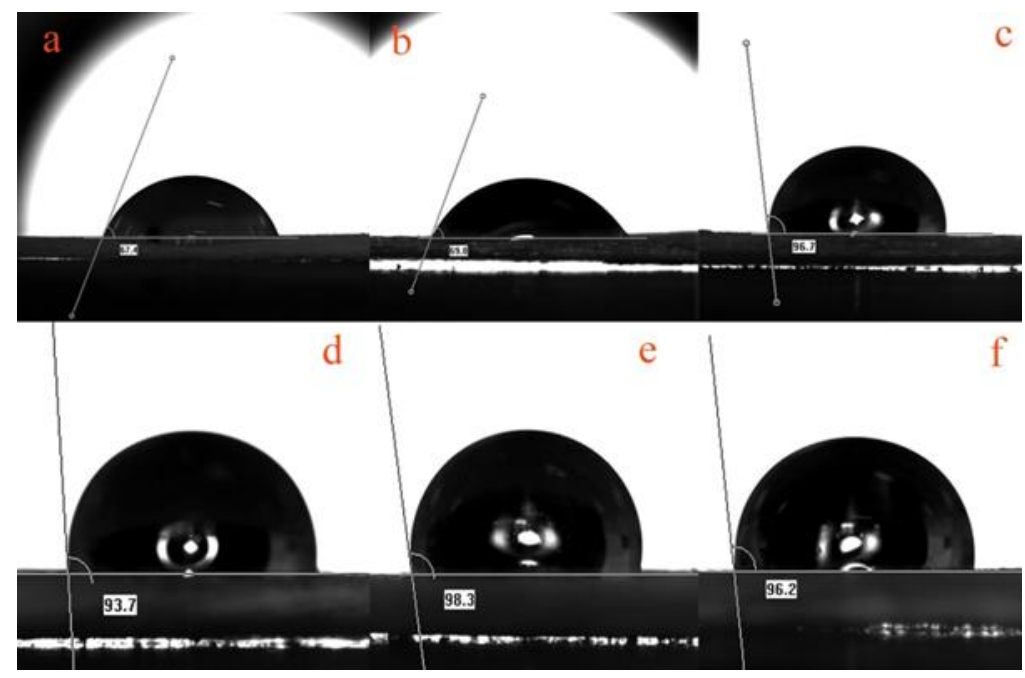

Fig. 6. Hydrophobic properties of wood surface coatings at different electroless Ni plating times (a: $0 \mathrm{~min}, \mathrm{~b}: 1 \mathrm{~min}, \mathrm{c}: 5 \mathrm{~min}, \mathrm{~d}: 10 \mathrm{~min}, \mathrm{e:} 15 \mathrm{~min}, \mathrm{f:} 20 \mathrm{~min}$ )

When the metal layer was deposited on the wood surface, it can accelerate the rate of autocatalytic reaction. With increasing durations of electroless nickel plating, the surface roughness of wood chips decreases gradually and the flatness of the surface coating was uniform. The structure of the metal layer was relatively dense, so the hydrophobic properties of the composite material were good. This result verifies the SEM analysis. A possible reason for the hydrophobicity of the composites with electroless Ni time of 15 min better than $20 \mathrm{~min}$ is that the thickness of the electroless layer on the wood surface gradually changes with time, resulting in a difference in the local roughness of the surface.

Table 2. Contact Angle of Electroless Ni Coating on Wood Surface at Different Electroless Ni Time

\begin{tabular}{|c|c|}
\hline Electroless Ni time ( $\mathrm{min})$ & Contact angle $\left(^{\circ}\right)$ \\
\hline 0 & 67.4 \\
\hline 1 & 69.0 \\
\hline 5 & 96.7 \\
\hline 10 & 93.7 \\
\hline 15 & 98.3 \\
\hline 20 & 96.2 \\
\hline
\end{tabular}

\section{Analysis of Electromagnetic Shielding Performance of Composite Materials}

The electromagnetic shielding effectiveness of the chemical plating on the wood surface gradually increased with the extension of the duration of electroless Ni plating (Wang and Li 2013), and its electromagnetic shielding effectiveness was between $55 \mathrm{~dB}$ and $65 \mathrm{~dB}$. The above experimental results showed that with the extension of duration of the plating, the resistance would always fluctuate within the range of 0.5 to $1 \Omega$. When the duration of the plating was $20 \mathrm{~min}$, the resistance value was $0.5 \Omega$, confirming the change rule of resistance gradient in the process. Wang and $\mathrm{Li}$ (2013) showed the electromagnetic 
shielding effectiveness of the chemical plating on the wood surface gradually increased with the extension of the duration of electroless Ni plating. Therefore, if a controlled resistance gradient structure can be developed, it is expected to break through the limitation of high absorption of electromagnetic waves. This study proposed the reasons for the improvement of the electromagnetic shielding effectiveness of wood-based conductivity gradient structure composites.

Figure 7 is a composite material electromagnetic shielding efficiency curve of the surface of the wood subjected to two cycles of electroless Ni plating. Since related literature (Wang and $\mathrm{Li}$ 2013) reported the electromagnetic shielding effectiveness of different durations of electroless Ni plating on the wood surface, this study only characterized the electromagnetic shielding effectiveness of wood-based conductivity gradient structure composites under optimal conditions. Then the results were compared with the wood-based conductivity gradient structure composite, which demonstrated the superiority of the electromagnetic shielding effectiveness of the material. The surface of the wood was treated with two cycles of electroless $\mathrm{Ni}$ plating, and the minimum value of the electromagnetic shielding of the composite material in the frequency range of $0.3 \mathrm{kHz}$ to $3.0 \mathrm{GHz}$ was $80 \mathrm{~dB}$. This result showed that the wood-based composite material had ideal electromagnetic shielding effectiveness.

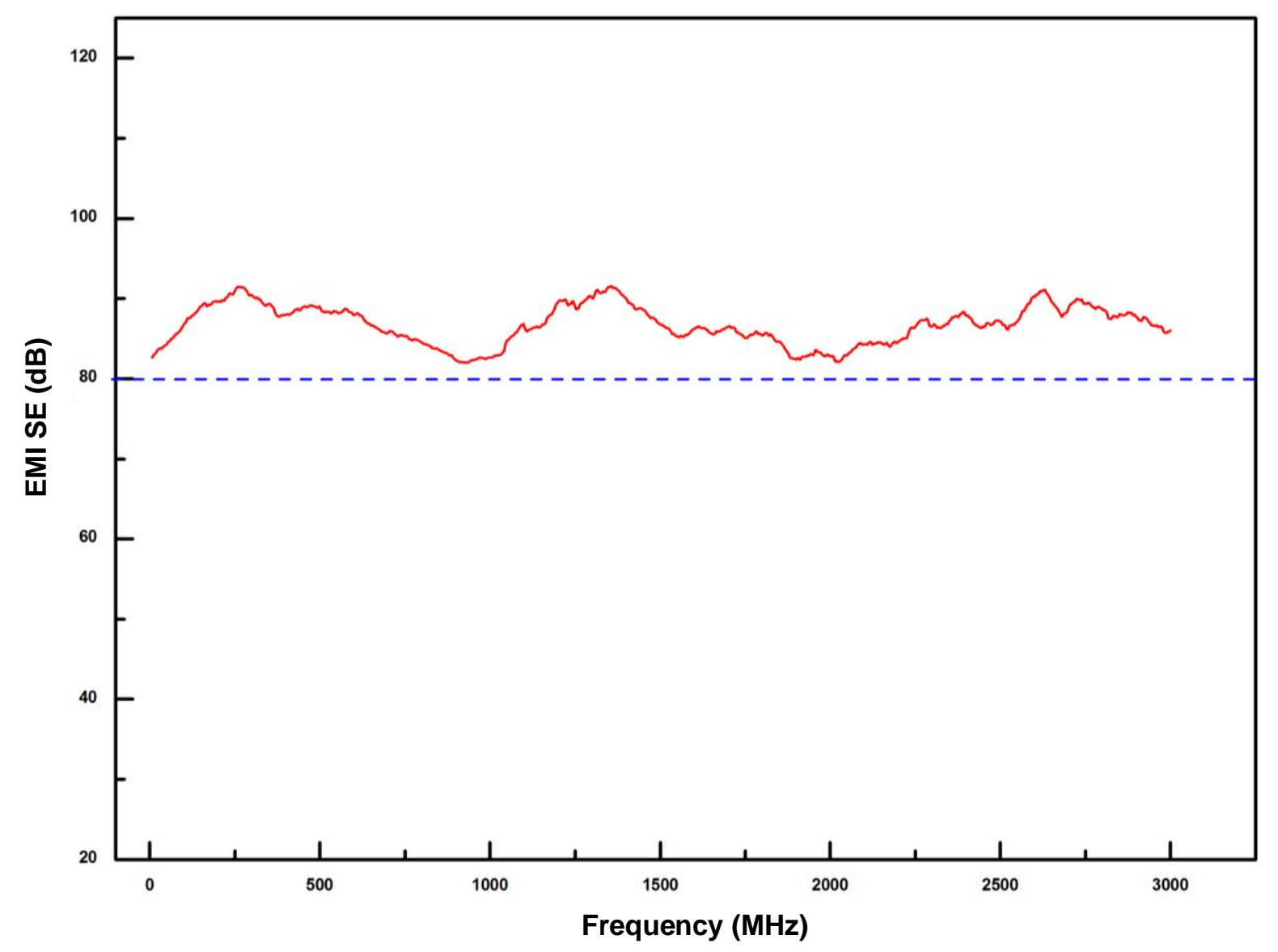

Fig. 7. Electromagnetic shielding effectiveness of wood-metal composite materials 


\section{Electromagnetic Shielding Mechanism of Resistance Gradient Structure Wood Matrix Composites}

Figure 8 is a schematic diagram of the electromagnetic shielding mechanism of the resistance gradient structure wood-based composite material. Microscopically, wood has a micro/nano multi-scale pore structure (Fig. 3a). Its natural skeleton form can be used as a matrix template for other materials. The surface of the porous channel is rich in a large number of active sites (carbon radicals, free hydroxyl groups, carbonyl groups, carboxyl groups, etc.) (Wang et al. 2018). As shown in the figure, the wood chips are placed in a chemical Ni-P plating solution, and $\mathrm{Ni}^{2+}$ in the plating solution is arranged along the inherent texture of the wood around the randomly distributed $\mathrm{Ni}$ to form a strip-shaped metal layer (Figs. 3, 3-c, and 3d). With the extension of the duration of electroless plating, the growth of Ni particles gradually extended around, and then filled the pores between the fibers, eventually forming a sheet-like structure, until the entire surface of the wood chip was evenly covered (Fig. 3f). The Ni, when present in elemental form, can catalyze the reduction of $\mathrm{Ni}^{2+}$. With the extension of the duration of plating, $\mathrm{Ni}$ particles gradually became closer, and the Ni layer on the wood surface gradually tended to be flat.

The wood that was used for the data of electromagnetic shielding effectiveness was treated via two depositions under the 20 min duration of electroless Ni plating, and the composite material with conductivity gradient structure indicated ideal electromagnetic shielding effectiveness. The reason was that high absorption was dominated by the interfacial polarization, as the polarization mode during microwave dielectric loss (Liu et al. 2016). Electromagnetic waves went through wood-based composite materials, and a large amount of free charge accumulated spontaneously between the metal Ni layer and the wood, resulting in macroscopic dipole moments and Debye relaxation, which accelerated the attenuation of electromagnetic waves ( $\mathrm{Li}$ et al. 2018). Second, the conductivity loss was undoubtedly another important factor. The better the conductivity of the material, the stronger the electromagnetic shielding effect (Liu et al. 2017). In this experiment, since the wood surface was treated with two cycles of electroless Ni plating, an ideal conductive structure was formed on the wood surface (Sheng et al. 2020). This ideal conductive structure made its resistance value only $20 \mathrm{~m} \Omega$. The composite material had good conductivity characteristics, which would promote the efficiency of accelerating the conversion of electromagnetic energy into thermal energy (Zhang et al. 2015; Wang et al. 2020). Besides, the gradient structure design will cause an "absorption-reflectionreabsorption" electromagnetic shielding mechanism (Xu et al. 2018, 2020), which can significantly attenuate electromagnetic wave backscatter (Chen et al. 2011; Liu et al. 2017), so that the shielding effect was better. Therefore, the surface of the wood was treated with two cycles of electroless Ni plating, and the wood-based composite material had ideal electromagnetic shielding effectiveness. 


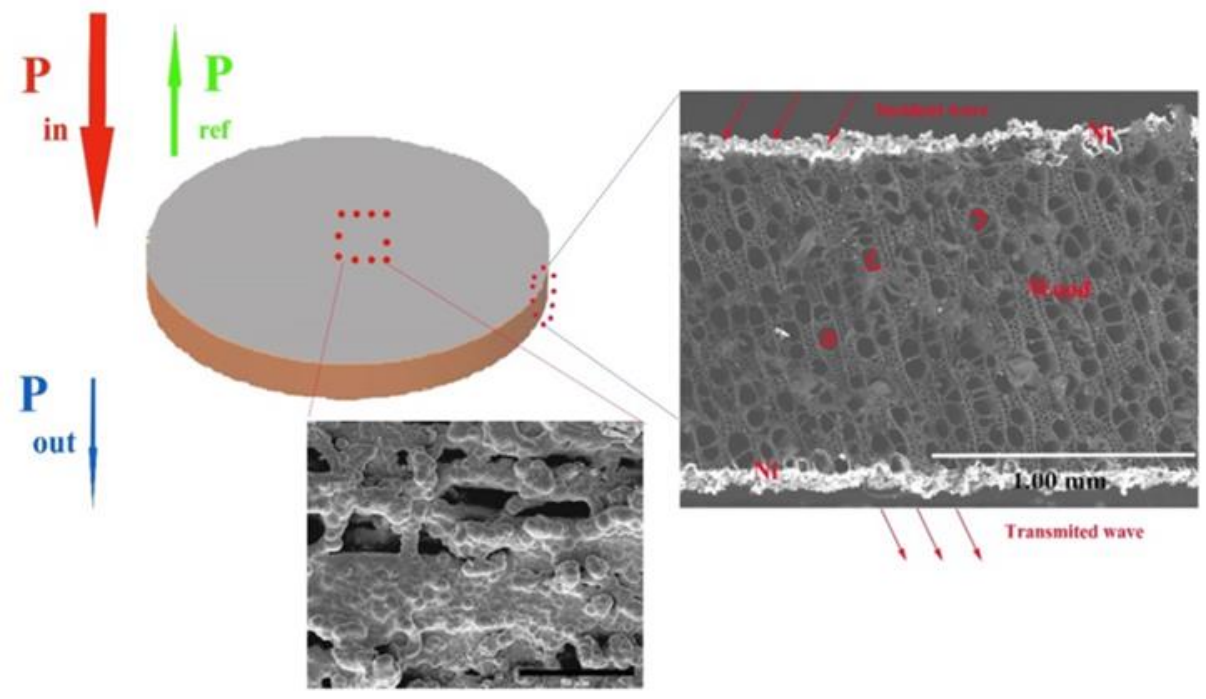

Fig. 8. Diagram of the electromagnetic shielding mechanism of wood metal composites

\section{CONCLUSIONS}

In this study, the time duration of electroless deposition of $\mathrm{Ni}$ was considered as an independent variable. The change rule and optimal development of the resistance gradient in the process of electroless $\mathrm{Ni}$ plating on the wood surface were analyzed under conditional performance according to the changes in the wood surface and internal micro-morphology of each time period. The conclusions were as follows:

1. With the extension of the duration of electroless Ni plating, the surface resistance of wood decreased from $12 \Omega$ to $1 \Omega$. When the duration of electroless plating exceeds 5 minutes, the surface resistance of wood will be in the range of 0.5 to $1 \Omega$. Here, the resistance was $0.5 \Omega$ when the duration of electroless plating was $20 \mathrm{~min}$.

2. The growth route of Ni particles was to form a strip-shaped metal layer along with the inherent pit structure of the wood. With the extension of the duration of electroless plating, the growth of $\mathrm{Ni}$ particles gradually extended to the surroundings, thereby filling the pores between the fibers and finally forming a sheet structure.

3. XRD showed that when the duration of electroless plating was 20 min, the wood surface was gradually covered with a metal layer. The wood surface coating gradually changed from amorphous to crystalline, which further verified the presence of $\mathrm{Ni}$ on the wood surface. 
4. When the duration of electroless Ni plating was $15 \mathrm{~min}$, the hydrophobic property of the wood-based metal composite was optimum, and the contact angle was $98.3^{\circ}$.

5. The average value of the electromagnetic shielding of the composite material in the frequency range from $0.3 \mathrm{kHz}$ to $3.0 \mathrm{GHz}$ was over $80 \mathrm{~dB}$.

\section{ACKNOWLEDGMENTS}

This work was supported by Natural Science Foundation of Inner Mongolia Autonomous Region (2019BS03014), the Start-up Project of Inner Mongolia Agricultural University High-level Talents Introduction Scientific Research (NDYB2016-24), The Colleges and Universities Science Research Project of Inner Mongolia Autonomous Region (NJZY18058), Science Research Innovation Projects of the Inner Mongolia Autonomous Region for Graduate (B20191134Z), and Science and Technology Innovation Leading Project of Inner Mongolia Autonomous Region (KCBJ2018013).

\section{REFERENCES CITED}

Amer, J. (2014). "Influence of multiple electroless nickel coatings on beech wood: Preparation and characterization," Composite Interfaces 21(3), 191-201. DOI: 10.1080/15685543.2014.854615.

Chen, M., Zhu, Y., and Pan, Y. (2011). "Gradient multilayer structural design of $\mathrm{CNTs} / \mathrm{SiO}_{2}$ composites for improving microwave absorbing properties," Materials \& Design 32(5), 3013-3016. DOI: 10.1016/j.matdes.2010.12.043

Chen, M. F., Zhou, W. J., and Chen, J. Z. (2019). "Rendering wood veneers flexible and electrically conductive through delignification and electroless Ni plating," Materials 12, 3198. DOI: 10.3390/ma12193198

Chen, Y. (2016). Experimental Study on Magnetic Expanded Graphite/Wood Fiber Electromagnetic Shielding Composite Board, Guangxi University, Nanning, China.

Cherian, B. M., Leão. A. L., and DeSouza, S. F. (2010). "Isolation of nanocellulose from pineapple leaf fibers by steam explosion," Carbohydrate Polymers 81, 720-725. DOI: $10.1016 /$ j.carbpol.2010.03.046

Guo, T. C. (2017). Research on Preparation and Performance of Woody Reflective Absorption Integrated Electromagnetic Shielding Material, Inner Mongolia Agricultural University, Huhhot, China.

He, W., Li, J. P., and Tian, J. X. (2018). "Characteristics and properties of wood/polyaniline electromagnetic shielding composites synthesized via in situ polymerization," Polymer Composites 39 (2), 537-543.DOI: 10.1002/pc.23966

Lee, T. W., Lee, S. E., and Jeong, Y. G. (2016). "Carbon nanotube/cellulose papers with high performance in electric heating and electromagnetic interference shielding," Composites Science \& Technology 131, 77-87.

DOI: 10.1016/j.compscitech.2016.06.003

Li, H., Jing, L., Ngoh, Z. L., and Tay, R. Y. (2018). "Engineering of high-density thinlayer graphite foam-based composite architectures with superior compressibility and excellent electromagnetic interference shielding performance," ACS Applied Materials \& Interfaces 10, 41707-41716. DOI: 10.1021/acsami.8b15240 


\section{Li, J. K. (2019). Physical Properties of Nano-Cu/ZnO Coated Wood-based Composites,} Northeast Forestry University, Harbin, China.

Li, Y., Liu, X., and Nie, X. (2018). "Multifunctional organic-inorganic hybrid aerogel for self-cleaning, heat-insulating, and highly efficient microwave absorbing material," Advanced Functional Materials 29(10), 1807624.DOI: 10.1002/adfm.201807624

Liang, R.R., Xiao, H., and Wang, N. (2017). "Shielding effectiveness of double-layer and multilayer electromagnetic shielding fabrics," Journal of Textiles Research 38(9), 5158. DOI: $10.13475 /$ j.fzxb.20161002508

Liu, J., Zhang, H. B., and Sun, R. (2017). "Hydrophobic, flexible, and lightweight mxene foams for high-performance electromagnetic-interference shielding," Advanced Materials 29(38), 1702367.1-1702367.6. DOI: 10.1002/adma.201702367

Liu, Q., Cao, Q., and Bi, H. (2016).“CoNi@SiO $\mathrm{Si}_{2} @ \mathrm{TiO}_{2}$ and CoNi@Air@ $\mathrm{TiO}_{2}$ microspheres with strong wideband microwave absorption," Advanced Materials 28(3), 486-490.

Liu, X., Yin, X., and Kong, L. (2014). "Fabrication and electromagnetic interference shielding effectiveness of carbon nanotube reinforced carbon fiber/pyrolytic carbon composites," Carbon 68, 501-510. DOI: 10.1016/j.carbon.2013.11.027

Liu, Y. X., and Zhao, G. J. (2012). Wood Science, China Forestry Publishing House, Beijing, China. DOI: 10.1002/adma.201503149

Nagasawa, C., Kumagai, Y., and Urabe, K. (1999). "Electromagnetic shielding particleboard with nickel-plated wood particles," Journal of Porous Materials 6(3), 247-254. DOI: 10.1023/A: 1009692232398

Pan, Y. F., Guo, Z. Q., and Guo, T. C. (2016). "The preparation, characterization, and influence of multiple electroless nickel-phosphorus (Ni-P) hollow composite coatings on micro-nano cellulose fibres,"Surface and Coatings Technology 298, 33-38. DOI: 10.1016/j.surfcoat.2016.01.061

Pan, Y. F., Wang, X., and Huang, J. T. (2016). "The preparation, characterization, and influence of multiple electroless Nickel-Phosphorus (Ni-P) composite coatings on poplar veneer," BioResources 11(1). 724-735. DOI:10.15376/biores.11.1.724-735.

Pan, Y. F., Wang, X., and Huang, J. T. (2017). "Influence of cross-sectional area on coatings of the metallized wood," Oxidation Communications 40(2), 853-861.

Poothanari, M. A., Abraham, J., Kalarikkal, N., and Thomas, S. (2018). "Excellent electromagnetic interference shielding and high electrical conductivity of compatibilized polycarbonate/polypropylene carbon nanotube blend nanocomposites," Industrial Engineering Chemistry Research 57, 4287-4297. DOI: $10.1021 /$ acs.iecr.7b05406

Qin, J. (2015). Physical Properties and Mechanical Relaxation of Chemical Silver Copper Poplar Veneer Multilayer Composites, Beijing Forestry University, Beijing, China.

Sheng, A., Ren, W., and Yang, Y. Q. (2020). "Multilayer WPU conductive composites with controllable electro-magnetic gradient for absorption-dominated electromagnetic interference shielding," Composites Part A 129, 105692,

DOI:10.1016/j.compositesa.2019.105692

Shi, C. H. (2016). Research on Electroless Nickel-Phosphorus-Nanoparticle Composite Coating on Wood Surface, Northeast Forestry University, Harbin, China.

Sudesh, P. G., Kihun, Y., and Ramanaskanda (2017). "MWCNT coated free-standing carbon fiber fabric for enhanced performance in EMI shielding with a higher absolute 
EMI SE," Materials 10(12), 1-11. DOI: 10.3390/ma10121350.

Wang, L. J., and Li, J. (2013). Electroless Plating of Wood, Science Press, Beijing, China.

Wang, L. J., Sun, L. L., and Li, J. (2010). "Electroless copper plating on Fraxinus mandshurica veneer using glyoxylic acid as reducing agent," BioResources 6(3), 3493-3504. DOI: 10.15376/biores.15.2.2371-238

Wang, L. L., Tay, B. K., and See, K. Y. (2009). "Electromagnetic interference shielding effectiveness of carbon-based materials prepared by screen printing," Carbon 47(8), 1905-1910. DOI: 10.1016/j.carbon.2009.03.033

Wang L., Wang Z., Ning G. Y., When, Y. L., and Wang, X. M. (2018). "Research progress of electromagnetic shielding," Materials Reports 32(7), 2320-2328. DOI: 10.11896/j.issn.1005-023X.2018.13.024

Wang, Y. (2017). Preparation and Performance Research of Electroless Shielding Particleboard of Thin Wood Chemical Copper Plating, Inner Mongolia Agricultural University, Huhhot, China.

Wang, Y., Wang, W., and Yu, D. (2020). "Multilayer-structured Ni-Co-Fe-P/polyaniline/ polyimide composite fabric for robust electromagnetic shielding with low reflection characteristic," Chemical Engineering Journal 380(12), 108-113. DOI: 10.1016/j.cej.2019.122553

Xu, Y. D., Yang,Y. Q., and Yan, D. X. (2018). "Gradient structure design of flexible waterborne polyurethane conductive films for ultraefficient electromagnetic shielding with low reflection characteristic," ACS Applied Materials \&Interfaces 10 (22), 19143-19152. DOI:10.1021/acsami.8b05129

Xu, Y. L., Uddin, A., and Estevez, D. (2020). "Lightweight microwire/graphene/silicone rubber composites for efficient electromagnetic interference shielding and low microwave reflectivity," Composites Science and Technology 189, 108022. DOI: 10.1016/j.compscitech.2020.108022

Zhang, Y., Huang,Y., and Zhang, T. F. (2015). "Broadband and tunable highperformance microwave absorption of an ultralight and highly compressible graphene foam," Advanced Materials 27(12), 2049-2053.DOI: 10.1002/adma.201405788

Zhou, T. T. (2011). Research on Wood Metal Base Treatment and Finishing Performance, Nanjing Forestry University, Nanjing, China.

Zhu, X. L. (2016). Multi-scale Simulation of Electrical Properties of Carbon Fiber Reinforced Wood Matrix Composites, Northeast Forestry University, Harbin, China.

Article submitted: May 18, 2020; Peer review completed: August 3, 2020; Revised version received: August 7, 2020; Accepted: August 8, 2020; Published: August 13, 2020.

DOI: $10.15376 /$ biores.15.4.7517-7531 